\title{
Use of Pesticides in Agricultural Products and Its Impact on Human Health: A Review
}

\author{
Dr. Tejinder Kaur (Corresponding Author) \\ Post-Doctoral Fellow \\ Department of Anthropology, Panjab University, Sector 14, Chandigarh, India \\ E-mail: kaurtejinder1985@gmail.com
}

Dr A. K. Sinha

Professor, Department of Anthropology

Panjab University, Sector 14, Chandigarh, India

E-mail: ksinha_anil@yahoo.com

Received: November 15, 2019 Accepted: November 26, 2019 Published: November 30, 2019

doi:10.5296/jfi.v3i1.16038ＵRL: http://dx.doi.org/10.5296/jfi.v3i1.16038

\begin{abstract}
In the present review paper, reviews of recent research findings on health effects of pesticides on agricultural products has been highlighted. The review reveals that although the concentration of the health literature has been on individuals who are in direct contact with pesticides, e.g. farmers, and the literature on preference elicitation has focused on those with indirect exposure like the consumers. On reviewing it was found that majority of farmers used crop rotation and control by hand methods, also they were aware about the pesticide use. In contrast, a few of the farmers used cultural and biological methods. Although they are interested to use seeds which are pest resistance, they cannot use those because of non-availability of seeds. Few of the studies, reported excessive sweating (36.5\%), burning/stinging/itching of eyes $(35.7 \%)$, dry/sore throat $(25.5 \%)$, and excessive salivation $(14.1 \%)$, all were more prevalent among sprayers. Men experienced excessive sweating and eye and throat problems as associated with pesticide exposure. One of the study disclosed that increased risk was observed for some specific classes of pesticides. The study concludes that there are many inherent problems in conducting large-scale experiments to directly assess the causation of the human health problems associated with the use of pesticides.
\end{abstract}




\section{Introduction}

The use of chemicals and nitrogen fertilizers in modern agriculture has grown dramatically over the past 30 years significantly increasing the productivity. Simultaneously, this has also increased the concentration of pesticides in food and in our environment, with associated negative effects on human health. Currently, approximately 600 active pesticide ingredients are used, but adequate toxicologic data are available for only approximately 100 of these. Environmental exposure of humans to agrichemicals is common and results in both acute and chronic health effects, including acute and chronic neurotoxicity (insecticides, fungicides, fumigants), lung damage (paraquat), chemical burns (anhydrous ammonia), and infant methemoglobinemia (nitrate in groundwater) (Weisenburger, 1993).

Presently, a few environmental issues have aroused public concern due to the exposure to pesticides, especially with respect to children's health. Regardless of numerous published studies on the relationships between exposure to pesticides and human health, controversy always surrounds these associations. Because the randomized controlled trials on the health effects of potentially harmful chemicals was not possible to conduct and also, because of the difficulty in measuring exposure to pesticides and the limitations characteristic in observational studies, the effects of pesticides on human health is still unsure.

Pesticides are one of the few lethal substances released deliberately into the environment to destroy living organisms (e.g., weeds (herbicides), insects (insecticides), fungus (fungicides), and rodents (rodenticides)). Although the term pesticide is often misunderstood to refer only to insecticides, it is also applicable to herbicides, fungicides, and various other substances used to control pests' (Matthews, 2006). Pesticides are used in public health activities to control vector-borne diseases (e.g., malaria and dengue) and unwanted plants (e.g., grass and weeds) in ornamental landscaping, parks, and gardens. They are also useful in suppressing the proliferation of insects, pests, bacteria, fungi, and algae in electrical equipment, refrigerators, paint, carpets, paper, cardboard, and food packaging materials (Gilden et al., 2010).

Agriculture is the largest consumer (around 85\% of world production) of pesticides to chemically control various pests. Due to increasing global agricultural productivity the use of chemical pesticides had increased considerably, resulting in diminishing the insect-borne, endemic diseases and protecting/restoring plantations, forests, harvested wood products, homes and fiber (Ecobichon, 2000). Presently pesticides are valued in developing countries, mostly those in tropical regions in search of entering the global economy by providing off-season fresh fruits and vegetables to countries in more temperate climates. It has been seen that many developing countries are in midway phases with migration of the agricultural workers to urban centers with the aim of search of better-paying jobs, leaving fewer people responsible for raising traditional foods for themselves and for the new, industrialized workforce.

Pesticides, may be harmful to people who are exposed to it even, very low levels of exposure may have adverse health effects at early development (Damalas \& Eleftherohorinos, 2011) through occupational (or home) use, eating foods or liquids containing pesticide residue, or 


\section{Macrothink}

inhalation (or contact) of pesticide-contaminated air (Pimentel et al., 2013). Although, unintentional contact to pesticides can be extremely hazardous to humans and other living organisms as they are designed to be poisonous (Sarwar, 2015). The physical makeup, behaviour, and physiology of children make them more susceptible to pesticides than adults (Mascarelli, 2013).

Pesticides have profoundly improved the human condition. Their dramatic effects in preventing crop loss and controlling vectors of disease have led to their acceptance and expanded use throughout the world. However, the powerful chemicals for killing pests have raised concern that they are agents of environmental pollution and human disease. During the past 50 years, agricultural intensification has caused many wild plant and animal species to go extinct both regionally or nationally and has intensely changed the functioning of agro-ecosystems. Agricultural intensification has multiple components, such as loss of landscape elements, enlarged farm and field sizes and larger inputs of fertilizer and pesticides. Having said that, it has to be mentioned that very little is known about the relative contribution of these variables to the large-scale negative effects on biodiversity. In the present review article, the impacts of various components of agricultural intensification on species diversity of wild plants, carabids and ground-nesting farmland birds and on the biological control of aphids have been focused.

\subsection{Toxicological Classification of Pesticides}

Pesticide differs in their physical, chemical and identical properties from one class to other as a result the classification is based on their properties. Also, synthetic pesticides do not occur in nature and are manmade chemicals, and they are categorized into various classes depending on the needs. Currently, there are three most popular method of pesticides classification suggested by (Drum, 1980), are: (i) classification based on the mode of entry, (ii) classification based on pesticide function and the pest organism they kill, and (iii) classification based on the chemical composition of the pesticide.

\subsection{Based on Toxicity of Pesticides}

World Health Organization (WHO) classified pesticides into four categories depending on the health risk associated with pesticides and their toxic behaviour. An experiment was conducted by WHO, on rats and other laboratory animals by administering a dose of pesticide then estimation of the median lethal dose (LD50) that produces death in $50 \%$ of exposed animals was done. 
Table 1. WHO classifications of pesticides (WHO, 2009)

\begin{tabular}{|c|c|c|c|c|}
\hline $\begin{array}{l}\text { WHO } \\
\text { class }\end{array}$ & Toxicity level & $\begin{array}{l}\text { LD50 for } \\
\text { Oral }\end{array}$ & $\begin{array}{l}\text { (mg/kg body weight) } \\
\text { Dermal }\end{array}$ & Examples \\
\hline Class Ia & $\begin{array}{l}\text { Extremely } \\
\text { hazardous }\end{array}$ & $<5$ & $<50$ & $\begin{array}{l}\text { Parathion, } \\
\text { Dieldrin }\end{array}$ \\
\hline Class Ib & Highly hazardous & $5-50$ & $50-200$ & $\begin{array}{l}\text { Eldrin, } \\
\text { Dichlorvos }\end{array}$ \\
\hline Class II & $\begin{array}{l}\text { Moderately } \\
\text { hazardous }\end{array}$ & $50-2000$ & $200-2000$ & $\begin{array}{l}\text { DDT, } \\
\text { Chlordane }\end{array}$ \\
\hline Class III & Slightly hazardous & $>2000$ & $>2000$ & Malathion \\
\hline Class IV & $\begin{array}{l}\text { Unlikely to present } \\
\text { acute hazard in } \\
\text { normal use }\end{array}$ & $>=5000$ & & $\begin{array}{l}\text { Carbetamide, } \\
\text { Cycloprothrin }\end{array}$ \\
\hline
\end{tabular}

Table 1 shows the ranking class from lowest to highest toxicity in numbers I through IV indicates extremely toxic, highly toxic, moderately toxic, slightly toxic, respectively.

\subsection{Potential Impact on Human Health}

Use of pesticides worldwide has resulted in different cases of acute and chronic poisoning, with effects of varying hazard on human health, from mild effects to death (Dawson et al., 2010). Roughly three million cases turn up globally each year due to acute pesticides poisoning. Overall out of these three million pesticide-poisoning cases, two million are suicide attempts, and the rest are due to occupational or accidental poisoning (Singh \& Mandal, 2013).

Pesticides exposure happens while preparing the spray solutions, loading in the spray tank and also while applying the pesticide. However, continued contact to sub lethal amount of pesticides by humans for an extended period of time, results in chronic illnesses where the symptoms are not instantly apparent but are manifested at a later stage (Germany, 2012). Such health effects depend upon the nature of the substance, the dose received, route of exposure such as inhalation, ingestion or skin absorption and individual susceptibility. According to some studies the occurrence of chronic health hazards, e.g., cancers, diabetes, depression, neurological deficits, respiratory diseases, and fertility problems, are certainly due to pesticide use (Bourguet \& Guillemaud, 2016). Epidemiologically speaking, there is a possible association between pesticide exposure and infertility, breast, prostate and ovarian cancer, and nervous system cancers (Fleming et al., 2003). Also, quite a lot of health problems such as Parkinson's disease, disruption of glucose homeostasis has also been linked with pesticides induced oxidative stress (Mostafalou \& Abdollahi, 2013). 


\section{$\underline{\Lambda \text { Macrothink }}$}

\section{Review of Literature}

\subsection{Pesticides and Cancer}

The relationship between 45 common agricultural pesticides and prostate cancer incidence in a prospective cohort study of 55,332 male pesticide applicators from Iowa and North Carolina having no prior history of prostate cancer was conducted by Alavanja et al. (2003). The incidence of cancer was determined through population-based cancer registries from enrollment through December 31, 1999, whereas self-administered questionnaires at enrollment (1993-1997) was used for data collection. A prostate cancer standardized incidence ratio was computed for the cohort. Odds ratios were computed for individual pesticides and for pesticide use patterns identified by means of factor analysis. A prostate cancer standardized incidence ratio of 1.14 (95\% confidence interval: $1.05,1.24)$ was observed for the Agricultural Health Study cohort. Study concluded that the use of chlorinated pesticides and methyl bromide over 50 years of age among applicators were significantly associated with prostate cancer risk.

An increased risk of prostate cancer among study subjects was observed among the people with family history of prostate cancer but not among those with no family history.

Shetty (2004) conducted a study based on a detailed field investigation conducted in four states (Karnataka, Andhra Pradesh, Maharashtra and Punjab) to determine the effects of the use (or misuse) of pesticides on the farming system, health of farmers and pest resistance. A total of 300 samples which comprised of farmers, from 48 randomly selected villages belonging to the pesticide use predominant areas were selected. These areas were selected on the basis of crops grown and pesticide consumption pattern. Results showed that the farmers rely heavily on pesticides for pest control. It was found that the respondents in the pesticide hot spots prefer to grow cotton, paddy, vegetables and crops that are in demand in the market, as also those that give them better returns. Monoculture of such crops has resulted in increased incidence of pests and diseases. The respondents were of the opinion that chemical methods of pest control are very effective in combating serious pest infestation; as a result, pesticides take up 25-50 per cent of the cost of cultivation in these regions. The respondents have adopted prophylactic and remedial use of these chemicals.

Arya (2005) released a comprehensive report based on review done on pesticide exposure and health risk, concluding that various pesticides their adverse health effects. The pesticide industries declare they are "safe" when used according to the directions mentioned, since they are studied and approved by governmental agencies because they are by many municipalities, including Canada's three largest, and the province of Quebec have acted out bans on cosmetic use of pesticides, largely in response to health concerns.

On evaluating the report, the importance of regulation of pesticides and the limitations of studies, it shows that on the basis of evidence available to date, there should be a ban on cosmetic use of pesticides by public health.

Lee et al. (2005) in their study evaluated the risk of the adult glioma associated with farming and agricultural pesticide use. For the purpose of data collection telephone interviews were 


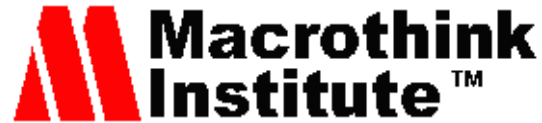

conducted with men and women diagnosed with gliomas $(n=251)$ between 1988 and 1993 and controls $(n=498)$ randomly selected from the same geographical area whereas the population-based case control study was conducted in eastern Nebraska. The results showed that there were significant associations between some specific agricultural pesticide exposures and the risk of glioma among male farmers but not among female farmers in Nebraska.

A population-based case-control study was carried out by Miligi et al. (2006) in order to investigate the association between hematolymphopoietic malignancies and occupational exposures, including pesticides. 9 out of 11 studied areas in Italy were agricultural or mixed areas. In the study the control group consist of a random sample of the population residing in each area. All newly diagnosed cases of hematolymphopoietic malignancies were collected in a 3-year period (1991-1993). The exposures in agriculture was estimated by the use of an agricultural questionnaire with 24 crop-specific questionnaires; expert agronomists who reviewed the collected information for each subject and translated it into pesticides histories. A total of 1925 cases and 1232 controls were interviewed in the nine agricultural areas. Results revealed an increased risk only for certain specific classes of pesticides. Furthermore, a non-statistically significant increased risk of non-Hodgkin's lymphoma (NHL) was observed for subjects who were exposed to phenoxy herbicides without using protective equipment and a significant increased risk for exposure to 2, 4-dichlorophenoxy acetic acid (2,4-D).

Bassil et al. (2007) reviewed literature documenting the associations between pesticide use and cancer. For the review purpose MEDLINE, PreMedline, CancerLit, and LILACS were searched to find studies published between 1992 and 2003 on non-Hodgkin lymphoma, leukemia, and 8 solid-tumour cancers: brain, breast, kidney, lung, ovarian, pancreatic, prostate, and stomach cancer. The review assessment was done by a team of 2 trained reviewers and rated based on methodological quality according to a 5-page assessment tool and a global assessment scale. The studies rated below a global score of 4 out of 7 were excluded. Results demonstrate a positive association between non-Hodgkin lymphoma and leukemia with pesticide exposure. Also, in some studies a positive association was built between Children's and pregnant women's exposure to pesticides as was parents' exposure to pesticides at work.

A positive association between pesticide exposure and solid tumours was also established. A steady link was found for brain and prostate cancer. It was also found that kidney cancer in children and their parents' exposure to pesticides at work was associated. These associations were more applicable for high and prolonged exposures. Specific weaknesses and inherent limitations in epidemiologic studies were noted, particularly around ascertaining whether and how much exposure had taken place.

Thakur et al. (2008) conducted a house-to-house survey in Talwandi Sabo and Chamkaur Sahib Community Development Blocks in Bathinda and Roop Nagar District respectively in Punjab state located in a northern part of India. The purpose of the study was to identify the number of existing cancer cases, and the number of cancer deaths that occurred in the 
last 10 years. Age adjusted prevalence of confirmed cancer cases per 100,000 population was 125 (107/85315) in Talwandi Sabo and 72 (71/97928) in Chamkaur Sahib. Findings revealed that the prevalence of cancer of female reproductive system were common in Talwandi Sabo whereas cancer of blood and lymphatic system, esophagus, and bones were more common in Chamkaur Sahib. A comparison of randomly selected individuals from the villages where a cancer case or death due to cancer had occurred in last 2 years showed their involvement in cultivation, pesticide use, alcohol consumption and smoking were more common in Talwandi Sabo as compared to Chamkaur Sahib. Limited studies show that in drinking water the levels of heavy metals such as $\mathrm{As}, \mathrm{Cd}, \mathrm{Cr}, \mathrm{Se}, \mathrm{Hg}$ were higher, and pesticides such as heptachlor, ethion, and chloropyrifos were also higher in samples of drinking water, vegetables, and in blood in Talwandi Sabo as compared to Chamkaur Sahib.

According to a review by Abhilash and Singh (2009) pesticides play a significant role by keeping away many dreadful diseases. The thrust of the present paper was to review the technology of application of pesticides in India and recommend future strategies for the rational use of pesticides and minimizing the problems related to health and environment. It has been observed that the pesticides exposures are increasingly linked to immune suppression, hormone disruption, diminished intelligence, reproductive abnormalities and cancer. A huge mass of the population of India is involved in agriculture and as a result is exposed to the pesticides used during agriculture. The research advocates that the Indian average consumption of pesticide is very low than many other developed countries of the world. Also, not only the problem of pesticide residue is very high in India, but also it has affected the export of agricultural supplies in past years. Minimizing of human exposure to pesticides can be done through pesticide safety, regulation of pesticide use, proper application technologies, and integrated pest management.

A study by Oluwole and Cheke (2009) was based on commonly used pesticides and handling practices in the Irepodun/Ifelodun local government area of Ekiti State, Nigeria. For the purpose of data collection direct field observations was conducted and answers to a structured questionnaire from a random sample of 150 farming households was done. Out of the frequently used pesticides herbicides (48.3 per cent), fungicides (28.2 per cent) and insecticides (23.5 per cent), 86.7 per cent are classified as 'highly' hazardous by the World Health Organization (WHO) and have been barred in many developed countries. Almost, maximum number of farmers (94.7 per cent) had no formal training in how to use pesticides safely and with mixed different products. Various health issues experienced by farmers are discomforts ranging from eye irritation ( 91.3 per cent), skin problems ( 87.3 per cent), nausea (86.0 per cent), head ache (83.3 per cent) and vomiting (58.0 per cent). It was found that (61.3 per cent) pesticide applicators sprayed pesticides near the water bodies. Very few farmers informed decreasing trends in numbers of beneficial insects (27.3 per cent) and other animals ( 29.3 per cent). The results revealed that the farmers and authorities need to be made aware regarding the use of protective equipment and correct procedures when handling pesticides. It is also advised for stricter administration of existing pesticide regulation and monitoring policies to minimize the threats that the farmers' current practices pose to their 
health and to the environment.

Chitra et al. (2013) assessed the relationship between extent of pesticide use and signs and symptoms of illnesses due to exposure in a cross-sectional survey of 631 farmers (537 men and 94 women) in South India. Results approved that 433 farmers which counts to $(68.6 \%)$ sprayed pesticides by their own resulting in direct contact with pesticides. Also, more than $75 \%$ farmers used moderately or highly hazardous pesticides, $88 \%$ used no protection while handling pesticides and $50 \%$ of sprayers mixed different brands. The farmers who use pesticides on field reported excessive sweating (36.5\%), burning/stinging/itching of eyes (35.7\%), dry/sore throat $(25.5 \%)$, and excessive salivation (14.1\%). Among men, excessive sweating and eye and throat problems were significantly associated with exposure.

Dey et al. (2013) carried out a study in the three districts of Barak valley (Cachar, Karimganj and Hailakandi) Assam, India to find out the variety of pesticides that are used in the agriculture sector and their possible impact on the health of the farmers. The results revealed that the farmers regularly use pesticides ranging from high to enormously harmful categories. To name few are Organochlorides (work by disrupting the sending of nerve signals seem to cause this long-term damage to myelin coating), Organophosphates and Carbamates causing muscle weakness and paralysis. Multiple signs and symptoms of diseases/ physiological disorders were observed including the relative risk (RR) which was found to be high. The declining health condition of farmers in the region has increased due to lack of adoption of adequate protective measures. There were also evidences given by Sataka et al. (1997) of the chronic disruption of the acetylcholine mechanisms for carrying nerve signals from one nerve fibre to another, from the brain to the body.

Mahmood et al. (2016) conducted a review study to check the effects of Pesticides on Environment. The present study focused on the issues of organochlorines, (which are used as pesticides) hazards posed by pesticides to human health and on the environment that has raised concerns about the safety of pesticides. The study also throws light on the types of pesticides and the long-term effects of compounds on human health. Not only the pesticides are least biodegradable and their use is banned in many countries but also pesticides like organochlorines are very much in use in many places which results in serious health hazards. According to Agrawal et al. (2010), these pesticides causes water pollution, even at low concentration, these pesticides have a serious risk to the environment. The majority of farmers are unaware of the toxicity of pesticides and has no information about types of pesticides, their level of poisoning, hazards and safety measures to be taken before their use. As a result, toxic and environmentally persistent chemicals are used to kill pests which lead to intentional, incidental or occupational exposure (Sharma et al., 2012). Pesticides have also posed a serious hazard the marine and aquatic ecosystems. Presently, there is a need to integrate various disciplines to understand direct and indirect effects of pesticides on the environment (Macneale et al., 2010).

Dahab et al. (2017) the excessive use of pesticides has produced rising concerns about the negative effects on human health and the environment. Pesticides can enter the human body through inhalation, oral or dermal exposure, and well documented to be the main cause of 


\section{$\underline{\text { Mnstitute }}$ Macrothink}

several diseases such as cancer, respiratory diseases, skin diseases, endocrine disruption, and reproduction disorders. The devastation of natural enemies can activate pest problems as they play an important role in regulating pest population levels. The loss of predator species can also lead to secondary pest outbreaks, an increase in problems from species, which were not originally very damaging pests due to loss of their predators or parasites. Pesticides degenerate soil invertebrates including nematodes, micro-arthropods, earthworms, and other small organisms that play an important role in soil ecosystems. There are several means to protect human health and environmental hazards associated with pesticides in agriculture, including, development and use of safe and environment friendly pesticide formulations, application of alternative pest control strategies in an IPM approach such as host plant resistance and bio-control.

Kim et al. (2017) conducted a complete literature review to precisely describe the impact of pesticide exposure and its health outcome. For this purpose, the studies published mainly from 2010 to the present were considered and the following data sources were utilized: Medline, EMBASE, Sciencedirect, PubMed, psycINFO, and papers cited in that database. The present paper details about almost all types of pesticides and its various uses to control weeds and insect infestation in agricultural fields and various pests and disease carriers (e.g., mosquitoes, ticks, rats, and mice) in houses, offices, malls, and streets. In order to directly assess the causation of the human health problems associated with the use of pesticides a number of problems have been encountered. In addition to that, the statistical associations between certain pesticides and the incidence of some diseases cannot be ignored. Although such hazards range from short-term (e.g., skin and eye irritation, headaches, dizziness, and nausea) to chronic impacts (e.g., cancer, asthma, and diabetes), their risks are unexplainable due to the involvement of various factors (e.g., period and level of exposure, type of pesticide (regarding toxicity and persistence), and the environmental characteristics of the affected areas). This present paper was planned to present a broad review on pesticides with respect to their types, environmental distribution, routes of exposure, and health impacts.

According to a study by Louis et al. (2017), over all Organochlorine insecticides (OCs) have been used worldwide to control insects, although most have now been banned in developed countries. Basically, occupational and population based-studies among men has been the evidence for an association between OC exposures and cancer. The evaluation of the connection between the use of specific OCs and cancer among the wives of pesticide applicators in the Agricultural Health Study was done. Results depicts that (7.58\%) reported ever use of at least one OC, among them 287 were diagnosed with cancer. It revealed that most cancers were not associated with OC use. Multiple myeloma was associated with chlordane $(\mathrm{N}$ exposed $=6, \mathrm{RR}=2.71,95 \% \mathrm{CI} 1.12-6.55)$. Risk of glioma was increased among users of at least one OC $(\mathrm{N}$ exposed $=11, \mathrm{RR}=3.52,95 \% \mathrm{CI} 1.72-7.21)$ and specifically among lindane users ( $\mathrm{N}$ exposed $=3, \mathrm{RR}=4.45,95 \% \mathrm{CI} 1.36-14.55)$. A positive association between pancreatic cancer and lindane, and ER-PR- breast cancer and dieldrin was observed based on 3 exposed cases each.

Yadav and Devi (2017) presented a review study on classification of pesticides and its impact on human and environment. Pesticides are defined as substances or mixture of substance which 
differ in their physical, chemical and identical properties from one to other and their classification is based on these properties. Pesticides are also sorted into various classes depending on the basis of their needs. Pesticides are currently classified based on the mode of entry as pesticide function, the pest organism they kill, and the chemical composition of the pesticide. Whereas, WHO classified them into four classes based on toxicity of pesticides as, extremely dangerous, highly dangerous, moderately dangerous and slightly dangerous. Inadequate application of pesticides leads to severe toxic effect to the environment. The toxicity of insecticides to an organism is usually expressed in terms of the LD 50 (lethal dose 50 percent) and LC 50 (50 percent lethal concentration). Generally, pesticides do not differentiate between pests and another similar incidental life-form and kill them all.

\subsection{Pesticides Awareness}

Sabur and Molla (2001) opined that it is a common belief that pesticide application pollutes water \& air and they are harmful to farm labour. It has been seen that majority of the farmers cover their face during pesticide application, among all crops, comparatively more pesticides are applied for vegetables crops. The present study shows that farmers use excess pesticides for all crops except Banana (sagar) and Mango. Non-IPM (integrated pest management) farmers apply much higher amount of pesticides than IPM farmers. Majority of trained farmers are aware and use crop rotation and control by hand methods though a few of them use cultural and biological methods. Although the farmers are more in favour of using pest resistance seeds

but they cannot because of non-availability of seeds. The use of recommended doses of pesticides, for both IPM and non IPM farmers differ significantly. More IPM farmers express their view that pesticide application pollutes air as well as crop. The research concludes that training on IPM inspired farmers to adopt non-traditional pest control methods.

According to Gupta et al. (2004) India started pesticide production with manufacturing plant for DDT and benzene hexachloride (BHC) $(\mathrm{HCH})$ in the year 1952. The use of pesticides in India began in 1948 when DDT was imported for malaria control and BHC for locust control. The present study is a review study which opines that the production of pesticides has increased to approximately 85,000 metric tonnes where an approximately 145 pesticides registered for use. The first reported pesticides poisoning in India came from Kerala in 1958 where, over 100 people died after ingesting parathion contaminated wheat flour. Consequently, multiple cases of pesticide-poisoning have been reported including the Bhopal disaster case. Widespread use of these chemicals has resulted to numerous short-term and long-term harmful effects of these chemicals on health. In spite of the fact that the consumption of pesticides in India is still very low, about $0.5 \mathrm{~kg} / \mathrm{ha}$ of pesticides against 6.60 and $12.0 \mathrm{~kg} / \mathrm{ha}$ in Korea and Japan, there has been a high rate of contamination of food supplies with pesticide residues, basically due to non-judicious use of pesticides. It has been perceived that long-term, low-dose exposure are increasingly linked to human health effects such as immune-suppression, hormone disruption, diminished intelligence, reproductive abnormalities, and cancer. Problems of pesticide safety, regulation of pesticide use, use of biotechnology, and biopesticides, and use of pesticides obtained from natural plant sources 
such as neem extracts are recommended as some of the future strategies for minimizing human exposure to pesticides.

Ntow et al. (2006) conducted a small survey of 137 farmers who applied pesticides to access the farmers' perceptions of pesticides use and application in vegetable production. The study was conducted in Ghana which aimed at promoting safe agricultural practices in the field areas.

Information regarding the type, scope and extent of use of pesticides, knowledge of pesticides, and the perceptions about the chemicals' potential for harm were obtained from field surveys, interviews, questionnaires and analytical games. Data obtained were used to describe the status of use of pesticides in vegetable cultivation in Ghana. The associations between farmers' age and possible pesticide poisoning symptoms, their farm size and method of spraying pesticides, and their perception of pesticide hazard and its perceived effectiveness against pests were also examined statistically using $\chi 2$ tests. The results revealed that on large-scale vegetable farms of 6-10 acres, motorised sprayers were used also the knapsack sprayers were the most widely used type of equipment for spraying pesticides. Inappropriate attempts in the handling and use of pesticides caused possible poisoning symptoms among those farmers who generally did not wear protective clothing. Findings revealed that younger farmers ( $<45$ years of age) were the most exposed group, probably because they did more spraying than older farmers ( $>45$ years of age). Farmers did not necessarily associate hazardous pesticides with better pest control.

Acute pesticide poisoning is an important cause of morbidity and mortality in developing countries. Better preventive and management strategies can be developed if the incidence and pattern of acute poisoning are known. Murali, (2009) conducted a retrospective study for 15 years i.e., from (1990 to 2004). For the study a total of 2884 patients with mean age 27.8 years (range 13 to 82 years), with serious pesticide contamination were admitted during the study period (1918 men). The case records of all cases admitted with acute poisoning during the above-mentioned time period were reviewed and the results were compared to earlier studies. The commonest agents were anticholinesterases $(35.1 \%)$ and aluminum phosphide (26.1\%). Though no difference was observed in mortality over different months for different agents but a seasonal variation in anticholinesterase poisoning was observed (most cases occurring July to September) but not for aluminum phosphide. Maximum case fatality ratio was due to aluminum phosphide exposures followed by anticholinesterase agents. The case fatality ratios for aluminum phosphide and organophosphate poisonings declined since 2000 (which may be due to limited availability of $3 \mathrm{gm}$ tablets and improved intensive care) despite an increase in aluminum phosphide exposures. Although the incidence of acute pesticide poisoning increased over decades, there has been a decline in mortality for both aluminum phosphide and anticholinesterases.

Tripathi et al. (2014) attempted to validate monitoring methods for the ecological characterization of a hexachlorocylcohexane $(\mathrm{HCH})$ isomers contaminated soil site in Lucknow, North India. For the present study, focuses on the variations and diversity in plant species, microbial biomass, total organic carbon, soil dehydrogenase activity, and pesticide 
concentration both in soil and plant species. Also, the presence of ecologically sensitive species like earthworms, honey bees and butterflies in contaminated and non-contaminated soil sites were studied. Assessment of the variation of functional groups present in soil were done by FTIR analysis. Methodology consists of the germination assays of selected seeds which were conducted in both $\mathrm{HCH}$-contaminated and non-contaminated soils. Results highlights a significant difference $(\mathrm{p} \leq 0.01)$ for the studied variables in $\mathrm{HCH}$-contaminated site in comparison to the non-contaminated soil site and a negative correlation with the level of $\mathrm{HCH}$ contamination was established. It was interesting to note that about twenty-five plant species were collected from the control site, whereas seven species were reported from $\mathrm{HCH}$-contaminated site. The outcomes highlight the germination percentages of all the test plants to be significantly low in contaminated soil in addition to that the presence of honeybees, earthworms and butterflies were not spotted in the contaminated sites. The suggested way of ecological characterization is appropriate for (i) knowing the extent and level of $\mathrm{HCH}$ isomers contamination (ii) knowing the adaptive capacity of the contaminated soil system and (iii) for adopting suitable methodical frame works for the in-situ restoration of contaminated soil sites.

Sande et al. (2011) studied the hazards from fumigants proposed as alternatives for pre-plant soil fumigation in tomato production. The Environmental Impact Quotient (EIQ) was developed by Kovach et al. to assess the threats from methyl bromide and the recommended alternative fumigants to workers, consumers, beneficial arthropods, birds, fish, and bees was used. The results showed that iodomethane 98/2 has the lowest EIQ index value and field use rating and is the alternative with the lowest relative risk. Among environmental categories, workers and beneficial arthropods experience the highest relative risks from the proposed tomato fumigants, and fish and consumers the least risks.

\subsection{Government of India's Efforts to Eliminate Persistent Organic Pesticides}

The environment ministry has notified new Regulation of Persistent Organic Pollutants (POP) Rules, 2018 which ban the manufacture, trade, use, import and export of the seven toxic chemicals listed under the Stockholm Convention. POPs are those organic chemicals which are toxic to both humans and wildlife. The POPs when released into the environment remains there for years on end, become widely distributed throughout the environment as a result of natural processes involving soil, water and air, and accumulate in the fatty tissues of living organisms including humans. These POPs are widely distributed all over the world, even in places they were never used because of human activities.

\section{Research Methodology}

The studies published mainly from 2001 to 2017 were considered and the following data sources were utilized: Medline, Science Direct, PubMed, ResearchGate, JSTOR and papers cited in that database. The present paper details about types of pesticides its effects on human beings and its wide uses to control weeds and insect infestation in agricultural fields and various pests and disease carriers (e.g., mosquitoes, ticks, rats, and mice) in residential houses and surrounding areas. A few full-length articles were not available, in that case only the abstracts were considered for the review part. 
For the present study a total of 18 research articles were reviewed elaborately.

\section{Discussion}

Few of the studies on reviewing revealed that majority of trained farmers were aware and used crop rotation and control by hand methods. In contrast, very few farmers used traditional and natural methods. Although they are in favour of pest resistance seeds, they fail to do so because of un availability of seeds. According to some of the studies, on agricultural pesticides and cancer incidences, the use of chlorinated pesticides among applicators over 50 years of age and methyl bromide use were significantly associated with prostate cancer risk. Several other pesticides like butylate, Permethrin and phorate were the only chemicals observed to have a significant excess risk among those with no family history of cancer, but no significant effect modification was observed.

Study by Shetty (2004) concluded that cultivation of high demanding mono-crop had not only resulted in increased incidences of pests but also diseases. The respondents were of the opinion that chemical methods of pest control are very effective in combating serious pest infestation; as a result, pesticides take up 25-50 per cent of the cost of cultivation in these regions. Another study by Lee et al. (2005) enfolded a significant association between some specific agricultural pesticide exposures and the risk of glioma among male farmers and not in female farmers in Nebraska. Specific pesticide families and individual pesticides were associated with significantly increased risks among male farmers; however, most of the positive associations were limited to proxy respondents.

Ntow (2006) and Chitra et al. (2013) has somewhat similar findings in their respective studies. In the former, it was concluded that various inappropriate practices in the handling and use of pesticides caused possible poisoning symptoms among those farmers who generally did not wear protective clothing. It was interesting to note that younger farmers ( $<45$ years of age) were the most vulnerable group, probably because they did more spraying than older farmers ( $>45$ years of age). In the later, $88 \%$ farmers used no protection while handling pesticides. About $50 \%$ of sprayers mixed different brands. Prevalence of excessive sweating (36.5\%), burning/stinging/itching of eyes $(35.7 \%)$, dry/sore throat $(25.5 \%)$, and too much salivation $(14.1 \%)$ was experienced among pesticide sprayers. Sweating, eye problem and throat problems were significantly linked with exposure of pesticides among men. One of the study disclosed that increased risk was observed for. Furthermore, a non-statistically significant increased risk of non-Hodgkin's lymphoma (NHL) was observed for subjects who were exposed to phenoxy herbicides not using protective equipment and a significant increased risk for exposure to 2, 4-dichlorophenoxy acetic acid (2,4-D).

According to Abhilash and Singh (2009) established a positive association between pesticide exposure and solid tumors. The most stable associations were found between brain and prostate cancer. Also, an association was obtained between kidney cancer in children and their parents' exposure to pesticides at work. These associations were most consistent for high and prolonged exposures. In order to ascertain certain weaknesses and inherent limitations for whether and how much exposure of pesticide had taken place epidemiological studies were reviewed and noted. On the other hand, Thakur et al. (2008) identified the age 
adjusted prevalence of confirmed cancer cases per 100,000 population was $125(107 / 85315)$ in Talwandi Sabo and 72 (71/97928) in Chamkaur Sahib. The farmers often use pesticides ranging from high to extremely hazardous categories like Organochlorides (work by disrupting the sending of nerve signals seem to cause this long-term damage to myelin coating), Organophosphates and Carbamates causing muscle weakness and paralysis. The relative risk (RR) was observed to be high, also various signs and symptoms of diseases/ physiological disorders were observed. The increase in the declining state of health of farmers in the region was said to be due to lack of adoption of adequate protective measures.

It is interesting to note that WHO classified pesticides on four categories based on their toxicity.

These were extremely dangerous, highly dangerous, moderately dangerous and slightly dangerous. The improper application of most of the pesticides causes severe effects to living system and the environment also many pesticides fails to differentiate between pests and other similar incidental life-form and kill them all. The toxicity of insecticides to an organism is usually expressed in terms of the LD 50 (lethal dose 50 percent) and LC 50 (50 percent lethal concentration).

Kim et al. (2017) gave a comprehensive review on pesticides with respect to their types, environmental distribution, routes of exposure, and health impacts showed statistical associations between exposures to certain pesticides. Though such hazards vary from short-term (e.g., skin and eye irritation, headaches, dizziness, and nausea) to long-lasting impacts (e.g., cancer, asthma, and diabetes), their risks are difficult to clarify due to the involvement of various factors (e.g., period and level of exposure, type of pesticide (regarding toxicity and persistence), and the environmental characteristics of the affected areas).

\section{Summary and Conclusions}

Pesticides include dozens of chemical families, with hundreds of active ingredients, thousands of different formulations and many known or suspected adverse health outcomes.

The present study throws light on the types of pesticides and the long-term effects of compounds on human health. Though these pesticides are least biodegradable and their use is banned in many countries still these are used in abundance. Based on toxicity of pesticides, WHO classified them into four classes: extremely dangerous, highly dangerous, moderately dangerous and slightly dangerous. There are always two sides of a coin, apart from proving itself to be a boon for the farmers all around the world pesticides has also issues of hazards posed on human health and on the environment.

Improper application of pesticides can cause severe harmful effect to living system and the environment. Most pesticides do not distinguish between pests and other similar incidental life-form and kill them all. Acute pesticide poisonings, both occupational and non-occupational, with mild-to-fatal effects, continue to be a major issue and there is an urgent need for a valid global estimate. The study concludes that there are many inherent problems in conducting large-scale experiments to directly assess the causation of the human 
health problems associated with the use of pesticides.

Pesticides have also caused a dangerous threat on biological integrity of marine and aquatic ecosystems. To integrate the studies of different disciplines including toxicology, environmental chemistry, population biology, community ecology, conservation biology and landscape ecology is required in order to understand direct and indirect effects of pesticides on the environment (Macneale et al., 2010).

\section{Acknowledgements and Sponsoring Information}

We sincerely thank UGC (Dr. Radhakrishnan Post-Doctoral Fellowship in Humanities and Social Science), New Delhi for assisting us financially. We would also like to thank librarian, A. C. Joshi Library as well as Mrs. Ranjana, Assistant Librarian of the Department of Anthropology, Panjab University, Chandigarh for allowing us to access research materials needed for the present paper.

\section{References}

Abhilash, S. (2009). Pesticide use and application: An Indian scenario. Journal of Hazardous Material, 165(1-3), 1-12. https://doi.org/10.1016/j.jhazmat.2008.10.061

Agrawal, A., Pandey, R. S., \& Sharma, B. (2010). Water Pollution with Special Reference to Pesticide Contamination in India. J. Water Resource and Protection, 2, 432-448.

Alavanja, M. C. R., Claudine, S., Mustafa, D., Jay Lubin., Robert Tarone., Charles, F. L., ... Aaron, B. (2003). Use of Agricultural Pesticides and Prostate Cancer Risk in the Agricultural Health Study Cohort. American Journal of Epidemiology, 157(9), 800-814. https://doi.org/10.1093/aje/kwg040

Arya, N. (2005). Pesticides and Human Health. Canadian Journal of Public Health, 96(2), 89-92. https://doi.org/10.1007/BF03403667

Bassil, K. L., Vakil, C., Sanborn, M., Cole, D. C., Kaur, J. S., \& Kerr, K. J. (2007). Cancer health effects of pesticides. Canadian Family Physician October, 53(10), 1704-1711.

Bener, A., Lestringant, G., Beshwari, M., \& Pasha, M. A. (1999). Respiratory symptoms, skin disorders and serum IgE levels in farm workers. Allergie et Immunologie, 31, 52-56.

Bourguet, D., \& Guillemaud, T. (2016). The hidden and external costs of pesticide use. Sustainable Agriculture Reviews, 19, 35-120. https://doi.org/10.1007/978-3-319-26777-7_2

Buchel, K. H. (1983). Chemistry of Pesticides. John Wiley \& Sons, Inc. New York, USA.

Chitra, A. G., Muraleedharan, V. R., Swaminathan, T., \& Veeraraghavan, D. (2013). Use of Pesticides and its Impact on health of farmers in South India. International Journal of Occupation and Environmental Health, 12(3), 228-233. https://doi.org/10.1179/oeh.2006.12.3.228

Dahab, A. A. (2017). Environmental and Human Health Impacts of Pesticide Use in Agriculture. Pesticides, 1-31. 


\section{Macrothink}

Damalas, C. A., \& Eleftherohorinos, G. E. (2011). Pesticide exposure, safety issues, and risk assessment indicators. Int. J. Environ. Res. Public Health, 8(5), 1402-1419. https://doi.org/10.3390/ijerph8051402

Dawson, A. H., Eddleston, M., Senarathna, L., Mohamed, F., Gawarammana, I. et al. (2010). Acute Human Lethal Toxicity of Agricultural Pesticides: A Prospective Cohort Study. PLoS Med, 7(10), e1000357. https://doi.org/10.1371/journal.pmed.1000357

Dey, K. R., Choudhury, P., \& Dutta, B. K. (2013). Impact of pesticide use on the health of farmers: A study in Barak valley, Assam (India). Journal of Environmental Chemistry and Ecotoxicology, 5(10), 269-277.

Drum, C. (1980). Soil Chemistry of Pesticides. PPG Industries, Inc. USA.

Ecobichon, D. J. (2000). Our changing perspectives on benefit and risks of pesticides: A historical overview. Neuro Toxicology, 21, 211-218.

Fleming, L. E., Gómez, M. O., Zheng, D., Ma, F., \& Lee, D. (2003). National Health Interview Survey mortal - ity among US farmers and pesticide applicators. American Journal of Industrial Medicine, 43(2), 227-233. https://doi.org/10.1002/ajim.10162

Germany, P. (2012). Pesticides and health hazards: Facts and figures. Pestizide und Gesundheitsgefahren: Daten und Fakten, Bochum.

Gilden, R. C., Huffling, K., \& Sattler, B. (2010). Pesticides and health risks. J. Obstet. Gynecol. Neonatal. Nurs, 39(1), 103-110. https://doi.org/10.1111/j.1552-6909.2009.01092.x

Gupta, P. K. (2004). Pesticide exposure-Indian scene. Toxicology, 198, 83-90. https://doi.org/10.1016/j.tox.2004.01.021

Ki-Hyun, K., Kabir, E., \& Shamin, A. J. (2017). Exposure to pesticides and the associated human health effects. Science of the Total Environment, 575, 525-535. https://doi.org/10.1016/j.scitotenv.2016.09.009

Lee, W. J., Colt, J. S., Heineman, E. F., Comb, R. M., Weisenburger, D. D., Lijinsky, W., \& Ward, M. H. (2005). Agricultural pesticide use and risk of glioma in Nebraska, United States. Occupational and Environmental Medicine, 62(11), 786-792. https://doi.org/10.1136/oem.2005.020230

Louis, L. M., Lerro, C. C., Friesen, M. C., Andreotti, G., Koutros, S., Sandler, D. P., ... Freeman, L. E.(2017). A prospective study of cancer risk among Agricultural Health Study farm spouses associated with personal use of organochlorine insecticides. Environmental Health, 16(1), 95. https://doi.org/10.1186/s12940-017-0298-1

Macneale, K. H., Kiffney, P. M., \& Scholz, N. L. (2010). Pesticides, aquatic food webs, and the conservation of Pacific salmon. Frontiers in Ecology and the Environment, 8, 475-482.

Mahmood, I., Sameen, R. I., Kanwal, S., Alvina, G., \& Khalid, R. H. (2016). Effects of Pesticides on Environment. In K. R. Hakeem et al. (Eds.), Plant, Soil and Microbes (pp. 
253-269). Switzerland: $\quad$ Springer $\quad$ International Publishing. https://doi.org/10.1007/978-3-319-27455-3_13

Mascarelli, A. (2013). Growing up with pesticides. Science, 341(6074), 740. https://doi.org/10.1126/science.341.6147.740

Matthews, G. A. (2006). Pesticides: Health, Safety and the Environment. Blackwell Publishing,Oxford, UK.

Miligi, L., Costantini, A. S., Veraldi, A., Benvenuti, A., Vineis, P., Nanni, O., ... Vindigni, C. (2006). Cancer and pesticides: An overview and some results of the Italian multicenter case-control study on hematolymphopoietic malignancies. Annals of the New York Academy of Sciences, 1076, 366-377. https://doi.org/10.1196/annals.1371.036

Ming, Y., Jeremy, B., Jonathan, W. M., \& Ambikaipakan, S. (2013). Occupational Pesticide Exposures and Respiratory Health. Int. J. Environ. Res. Public Health, 10, 6442-6471. https://doi.org/10.3390/ijerph10126442

Mostafalou, S., \& Abdollahi, M. (2013). Pesticides and human chronic diseases: Evidences, mechanisms, and perspectives. Toxicology and Applied Pharmacology, 268, 157-177. https://doi.org/10.1016/j.taap.2013.01.025

Murali, R. (2009). Acute pesticide poisoning: 15 years' experience of a large North-West Indian hospital. $\quad$ Clinical Toxicology, $\quad 47(1), \quad 35-38$. https://doi.org/10.1080/15563650701885807

Ntow, W. J., Gijzen, H. J., Kelderman, P., \& Drechsel, P. (2006). Farmer perceptions and pesticide use practices in vegetable production in Ghana. Pest Management Science, 62(4), 356-365. https://doi.org/10.1002/ps.1178

Oluwole, \& Cheke. (2009). Health and environmental impacts of pesticide use practices: A case study of farmers in Ekiti State, Nigeria. International Journal of Agricultural Sustainability, 7(3), 153-163. https://doi.org/10.3763/ijas.2009.0431

Pimentel, D., Culliney, T. W., \& Bashore, T. (2013). Public Health Risks Associated with Pesticides and Natural Toxins in Foods. In E. B. Radcliffe, W. D. Hutchison, \& R. E. Cancelado (Eds.), Radcliffe's IPM World Textbook. University of Minnesota, St. Paul, MN.

Sabur, S. A., \& Molla, A. R. (2001). Pesticide Use, Its Impact on Crop Production and Evaluation of IPM Technologies in Bangladesh. Bangladesh J. Agric. Econs. XXIV(1\&2), 21-38.

Sande, D., Jeffrey, M., Michael, W., \& Jack, H. (2011). Environmental Impacts from Pesticide Use: A Case Study of Soil Fumigation in Florida Tomato Production. International Journal of Environmental Research and Public Health, 8(12), 4649-4661. https://doi.org/10.3390/ijerph8124649

Sarwar, M. (2015). The dangers of pesticides associated with public health and preventing of the risks. Int. J. Bioinfor. Biomed. Eng. 1(2), 130-136. 


\section{Macrothink}

Sataka, M .Y., Mido, M. S., Sethi, S. A., Iqbal, H. Y., \& Taguchi, S. (1997). Environmental toxicology (pp. 185-197). New Delhi, India: Discovery Publishing House.

Sharma, D. R., Thapa, R. B., Manandhar, H. K., Shrestha, S. M., \& Pradhan, S. B. (2012). Use of pesticides in Nepal and impacts on human health and environment. J Agric Environ., 13(6).

Shetty, P. K. (2004). Socio-ecological Implications of Pesticide Use in India. Economic and Political Weekly, 39(49), 5261-5267.

Singh, B., \& Mandal, K. (2013). Environmental impact of pesticides belonging to newer chemistry. In A. K. Dhawan, B. Singh, M. Brar-Bhullar, \& R. Arora (Eds.), Integrated pest management (pp. 152-190). Jodhpur, India: Scientific Publishers.

Thakur, J. S., Rao, B. T., Rajwanshi, A., Parwana, H. K., \& Kumar, R. (2008). Epidemiological Study of High Cancer among Rural Agricultural Community of Punjab in Northern India. Int. J. Environ. Res. Public Health, 5(5), 399-407. https://doi.org/10.3390/ijerph5050399

Tripathi, V., Dubey, R. K., Edrisi, S. A., Narain, K., \& Singh, et al. (2014). Towards the ecological profiling of a pesticide contaminated soil site for remediation and management. Ecological Engineering, 71, 318-325. https://doi.org/10.1016/j.ecoleng.2014.07.059

Weisenburger, D. D. (1993). Human health effects of agrichemical use. Human Pathology, 24(6), 571-576. https://doi.org/10.1016/0046-8177(93)90234-8

WHO. (2009). The WHO recommended classification of pesticides by hazard and guidelines to classification: 2009. World Health Organization, 20 Avenue Appia, 1211 Geneva 27, Switzerland.

Yadav, I. C., \& Devi, N. L. (2017). Pesticides Classification and Its Impact on Human and Environment. Environment Science and Engineering: Toxicology, (6), 140-158.

\section{Copyright Disclaimer}

Copyright for this article is retained by the author(s), with first publication rights granted to the journal.

This is an open-access article distributed under the terms and conditions of the Creative Commons Attribution license (http://creativecommons.org/licenses/by/4.0/). 